\title{
Risk factors associated with short dental implant success: a long-term retrospective evaluation of patients followed up for up to 9 years
}

Güzin Neda HASANOGLU ERBASAR ${ }^{(a)}$ Turgay Peyami HOCAOĞLU(b) Ramiz Can ERBASAR ${ }^{(c)}$

(a)Ankara Yıldırım Beyazıt University, Faculty of Dentistry, Department of Oral and Maxillofacial Surgery, Assistant Professor, Ankara, Turkey

(b) Cumhuriyet University, Faculty of Dentistry, Department of Oral and Maxillofacial Surgery, Assistant Professor, Sivas, Turkey

(c) Private Practice, Prosthodontic Specialist, Ankara, Turkey

Declaration of Interests: The authors certify that they have no commercial or associative interest that represents a conflict of interest in connection with the manuscript.

Corresponding Author:

Güzin Neda Hasanoglu Erbasar

E-mail: neda986@gmail.com

Submitted: April 24, 2018

Accepted for publication: February 27, 2019

Last revision: March 14, 2019
Abstract: This multicenter study aimed to identify the different implant- and patient-related risk factors for long-term short dental implant success. Through a retrospective chart review of three centers, patient information regarding demographic variables, smoking habits, history of periodontitis, systemic diseases, and medications in addition to the parameters for short implant placement including implant manufacturer, design, anatomical location, diameter and length, and type of placement was collected. For statistical analysis, univariate regression models were used at the implant and patient levels. A total of 460 short implants placed in 199 patients followed up for up to 9 years were reviewed. Survival rates of the short implants were $95.86 \%$ and $92.96 \%$ and success rates were $90 \%$ and $83.41 \%$ for implant- and patient-based analysis, respectively. Peri-implantitis was reported as the primary cause of short dental implant failure (34/46, 73.91\%). Univariate regression models revealed that female sex was strongly related to short implant success. In addition, smoking and history of periodontitis were found to have a significant negative influence on short implant success at the implant and patient levels. Taken together, these results support the use of short implants as a predictable longterm treatment option; however, smoking and history of periodontitis are suggested to be the potential risk factors for short implant success. Therefore, clinicians need to assess these potential risk factors and make treatment decisions accordingly.

Keywords: Dental Implants; Treatment Outcome; Risk Factors; Regression Analysis; Retrospective Study.

\section{Introduction}

The use of standard dental implants has become a highly predictable and effective treatment modality for the rehabilitation of complete

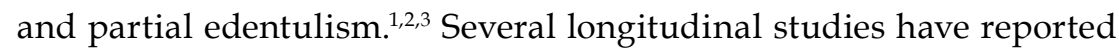
high survival rates of approximately $89 \%-96 \%$ over a 10 -year period in various patient populations using different dental implant systems. In addition, lower but acceptable success rates varying between 52\% and $79 \%$ were found in these studies based on the criteria selected for 
implant success measurement. ${ }^{4,5,6,7}$ However, in severe alveolar resorption, standard-length implant $(\geq 10 \mathrm{~mm})$ placement is not possible without additional surgical interventions including bone grafting, sinus floor augmentation, distraction osteogenesis, mandibular nerve transposition, zygomatic implant placement, and transmandibular implant placement. These procedures are associated with increased surgical morbidity, prolonged treatment times, and higher cost. ${ }^{8,9,10}$ However, the use of short implants is considered a major contribution to the field of implant dentistry and is a novel therapeutic option for patients with severe alveolar resorption. ${ }^{9}$ Although the predictability of short implants was initially controversial because of decreased bone-to-implant contact, ${ }^{11}$ several studies have reported short implants to have survival rates similar to those of standard-length implants. ${ }^{12,13,14}$

The adverse effects of tobacco use, chronic hyperglycemia, poor oral hygiene status, periodontitis history, and parafunctional habits on the survival and success of standard dental implants are chronicled in the literature, ${ }^{3,4,15}$ however, very few studies have evaluated the risk factors associated with the longterm success of short dental implants. ${ }^{11,16}$ Therefore, this multicenter, retrospective study aimed to identify the long-term influence of different implant- and patient-related factors on short implant success.

\section{Methodology}

This multicenter, retrospective study included 199 patients (84 men [42.21\%] and 115 women [57.79\%]; average age: $53.59 \pm 10.93$ years) referred to the departments of oral and maxillofacial surgery of Ankara Yildırım Beyazıt University (Ankara, Turkey) and Cumhuriyet University (Sivas, Turkey) in addition to a private practice for implantology in Ankara, Turkey. We examined the clinical files and radiographs of all patients who underwent dental implant placement between December 2007 and August 2016. Patients aged $\geq 18$ years who underwent treatment with at least one short implant with a cemented crown or supported cemented bridge were included in the study. Implants were considered short if their length was $\leq 9 \mathrm{~mm} .{ }^{17}$ Patients with a history of smoking habits, periodontitis, and systemic disease other than an absolute contraindication to implant surgery were included. However, patients who were undergoing treatment and those with implants noted on radiographic analysis without basic information were excluded from the study. The study protocol was approved by the Ethical Committee of Cumhuriyet University Medical Faculty (2017-10/02).

The surgical technique for implant placement followed a standard protocol under sterile conditions according to the manufacturer's recommendations. Four brands of dental implant systems used at the study centers were evaluated in the study: Straumann (Institute Straumann AG, Waldenburg, Switzerland), Astra Tech OsseoSpeed (Astra Tech AB, Mölndal, Sweden), MIS (MIS Implant Technologies Ltd., Shlomi, Israel), and SGS Dental (SGS International Ltd., Schaan, Liechtenstein).

Data regarding implant manufacturer, design (tissue level and bone level), anatomical location, diameter (ranging from 3.3 to $5.0 \mathrm{~mm}$ ), length (ranging from 4.0 to $9.0 \mathrm{~mm}$ ), and placement (immediate and conventional); smoking habits; history of periodontitis; systemic diseases; medications; and survival time were collected and recorded in a database. Implant success was evaluated based on the following criteria proposed by Albrektsson et al..$^{18}$ : absence of mobility after implant insertion; no evidence of peri-implant radiolucency; < $0.2-\mathrm{mm}$ annual bone loss following the first year of service; and absence of persistent and/ or irreversible signs and symptoms including pain, infection, neuropathy, paresthesia, or any violation of the mandibular canal. Implant survival was defined as the physical existence of any implant in the mouth.

Descriptive statistics and frequency distributions were generated for all demographic variables. Logistic regression models were constructed at the implant and patient levels for statistical analysis of the data. The implant-level model considered each implant as a unit of analysis to determine the influence of implant- and patient-related factors on the success of short implants. Further, the patient-level model considered each patient as a unit of analysis presenting or not presenting an unsuccessful implant. Only patient-related factors were included in the model to determine the factors that best predicted short implant success. Moreover, odds ratios and 95\% 
confidence intervals were calculated. A p-value of $<0.05$ was considered statistically significant, and all analyses were performed using SPSS Statistics, Version 20.0 (SPSS Inc., Chicago, USA).

\section{Results}

A total of 460 short dental implants including 344 Straumann, 93 Astra Tech OsseoSpeed, 11 MIS, and 12 SGS implants in 199 patients who were followed up for up to 9 years (6-104 months; average: $33.59 \pm 24.44$ months) were reviewed in the current study.

Of the included patients, 59 were classified as smokers $(29.65 \%), 58(29.15 \%)$ had a history of periodontitis, 21 had type II diabetes mellitus (DM) (10.55\%), and 7 had type I DM (3.52\%). Other systemic diseases noted in $46(23.12 \%)$ patients included hypertension $(\mathrm{n}=31)$, arrhythmia $(\mathrm{n}=2)$, asthma $(n=2)$, hypercholesterolemia $(n=2)$, hyperthyroid

Table 1. Frequency distribution of different variables in relation to patients.

\begin{tabular}{lcc}
\hline Variable & $\begin{array}{c}\text { Number of } \\
\text { patients }(\mathrm{n})\end{array}$ & $\begin{array}{c}\text { Percentage } \\
(\%)\end{array}$ \\
\hline Sex & & \\
Male & 84 & 42.21 \\
$\quad$ Female & 115 & 57.79 \\
Age at implant placement (years) & & \\
18-34 & 11 & 5.52 \\
35-59 & 130 & 65.33 \\
$\geq 60$ & 58 & 29.15 \\
Systemic diseases & & \\
None & 125 & 62.81 \\
Type I Diabetes Mellitus & 7 & 3.52 \\
Type II Diabetes Mellitus & 21 & 10.55 \\
Hypertension & 31 & 15.58 \\
Other systemic diseases & 15 & 7.54 \\
Smoking habits & & \\
No & 140 & 70.35 \\
Yes & 59 & 29.65 \\
History of periodontitis & & \\
No & 141 & 70.85 \\
Yes & 58 & 29.15 \\
Total & 199 & \\
\hline
\end{tabular}

$(n=4)$, gastric ulcer $(n=2)$, osteoporosis $(n=1)$, and rheumatic diseases $(n=2)$. In total, 263 implants were installed in the maxilla (57.17\%) and 197 in the mandible (42.83\%); 422 implants were inserted in posterior areas (91.73\%). The specific patient and implant characteristics are summarized in Tables 1-3.

At the end of the study period, a total of 19 implants were lost in 14 patients. The vast majority of implants $(16 / 19,84.21 \%)$ were lost following occlusal loading (late loss) (Table 4). Further, the overall survival and success rates of short dental implants were calculated using implant- and patient-based analysis, with survival rates being $95.86 \%$ and $92.96 \%$ and success rates being $90 \%$ and $83.41 \%$, respectively. Peri-implantitis was reported as the primary cause of implant failure (34/46, 73.91\%) (Table 4).

Univariate binary logistic regression revealed that female sex was positively associated with short implant success at the implant $(p=0.009)$ and patient $(p=0.005)$ levels. At the implant level, a history of periodontitis $(p=0.021)$ was negatively associated with short implant success, and the possibility of implant success decreased by 0.934 times per unit with increasing number of cigarettes smoked per day $(p=0.001)$ (Table 5). At the patient level, a significant negative correlation was found between history of periodontitis and short implant success $(p=0.043)$, also the possibility of implant success being decreased by 0.920 times per unit with increasing number of cigarettes smoked per day $(p=0.001)$ (Table 6). The remaining variables did not show a significant correlation with short implant success at the patient or implant level.

\section{Discussion}

The use of short implants is based on the biomechanical rationale that most load-bearing stress is generated at the neck portion of an implant, whereas a very small amount is transmitted to the apical portion. ${ }^{919}$ However, initial clinical research reported lower survival rates for short dental implants than for standard-length implants. ${ }^{20,21,22}$ The overall survival and success rates of short implants have increased and their prognosis has become more predictable, possibly due to the recent improvements 
Table 2. Smoking status and periodontitis history distribution of patients according to sex.

\begin{tabular}{|c|c|c|c|c|c|c|}
\hline \multirow{3}{*}{ Variable } & \multicolumn{6}{|c|}{ Sex } \\
\hline & \multicolumn{2}{|c|}{ Male } & \multicolumn{2}{|c|}{ Female } & \multicolumn{2}{|c|}{ Total } \\
\hline & $\mathrm{n}$ & $\%$ & $\mathrm{n}$ & $\%$ & $n$ & $\%$ \\
\hline \multicolumn{7}{|l|}{ Smoking habit } \\
\hline No & 58 & 41.43 & 82 & 58.57 & 140 & 100 \\
\hline Light smoker (<10 cigarettes/day) & 3 & 23.08 & 10 & 76.92 & 13 & 100 \\
\hline Moderate smoker (10-19 cigarettes/day) & 5 & 25 & 15 & 75 & 20 & 100 \\
\hline Heavy smoker ( $\geq 20$ cigarettes/day) & 18 & 69.23 & 8 & 30.77 & 26 & 100 \\
\hline Total & 84 & 42.21 & 115 & 57.79 & 199 & 100 \\
\hline \multicolumn{7}{|l|}{ History of periodontitis } \\
\hline No & 49 & 35 & 91 & 65 & 141 & 100 \\
\hline Yes & 35 & 60.34 & 23 & 39.66 & 58 & 100 \\
\hline Total & 84 & 42.42 & 114 & 57.58 & 199 & 100 \\
\hline
\end{tabular}

Table 3. Frequency distribution of different variables in relation to short implants.

\begin{tabular}{lcc}
\hline Variable & $\begin{array}{c}\text { Number of } \\
\text { patients }(\mathrm{n})\end{array}$ & $\begin{array}{c}\text { Percentage } \\
(\%)\end{array}$ \\
\hline $\begin{array}{l}\text { Manufacturer of short implant } \\
\text { Straumann }\end{array}$ & 344 & 74.78 \\
Astra Tech OsseoSpeed & 93 & 20.22 \\
MIS & 11 & 2.39 \\
SGS & 12 & 2.61 \\
Total & 460 & 100 \\
Anatomical location & & \\
Anterior mandible & 4 & 0.87 \\
Posterior mandible & 193 & 41.96 \\
Anterior maxilla & 34 & 7.39 \\
Posterior maxilla & 229 & 49.78 \\
Total & 460 & 100 \\
Design of implant & & \\
Tissue level & 204 & 44.34 \\
Bone level & 256 & 55.66 \\
Total & 460 & 100 \\
Implant placement & & 9.78 \\
Conventional & 460 & 100 \\
\hline Immediate & & \\
Total & 45 & 90.22 \\
\hline
\end{tabular}

in the mechanical properties and surface morphologies of implants. ${ }^{910,11,16}$ This retrospective study aimed to determine the survival and success rates of short dental implants and evaluate the local and systemic risk factors associated with long-term implant success in patients followed up for up to 9 years. Only a few studies in the literature have investigated the long-term prognosis of short implants. In addition, the definition of short implants varies among these studies. Some studies regarded 10-mm-long implants as short implants, and most other studies only included implants of 8- and/or 9-mm length. . $3,24,25^{-}$ In the current study, we regarded $\leq 9$-mm-long implants ranging from 4 to $9 \mathrm{~mm}$ in length as short implants. The results of this study demonstrated high survival and success rates in implant- and patientbased analyses, consistent with the findings of other long-term studies., ${ }^{911,26}$ Similarly, systematic reviews and a meta-analysis of short implants reported high survival and success rates ranging from $88.1 \%$ to $100 \%$ and $89.5 \%$ to $100 \%$, respectively. ${ }^{8,27,28}$ Conversely, most reports only specified simple survival and success rates of short implants in a favorable patient population without considering other components that negatively impact implant success. ${ }^{23,29,30}$ Additionally, literature assessments of potential risk factors for short implant success/survival with inappropriate statistical analysis may lead to an incorrect conclusion. The main strength of this study is not only its multicenter design comprising a larger patient population than previous studies but also the inclusion of all patients treated with short implants installed at different anatomical locations regardless of their accompanying medical or other conditions. Furthermore, as a statistical method, 
Table 4. Distribution of the different variables in relation to failed (unsuccessful) short implants.

\begin{tabular}{|c|c|c|c|c|c|c|c|c|c|c|c|c|}
\hline \multicolumn{5}{|c|}{ Patient } & \multicolumn{5}{|c|}{ Implant } & \multicolumn{3}{|c|}{ Implant fail/loss } \\
\hline $\begin{array}{l}\text { Age } \\
\text { (years) }\end{array}$ & Sex & $\begin{array}{c}\text { Medical } \\
\text { history }\end{array}$ & $\begin{array}{c}\text { Smoking } \\
\text { habit }\end{array}$ & $\begin{array}{c}\text { History of } \\
\text { periodontitis }\end{array}$ & Localization & $\begin{array}{l}\text { Length } \\
(\mathrm{mm})\end{array}$ & $\begin{array}{l}\text { Diameter } \\
(\mathrm{mm})\end{array}$ & Design & $\begin{array}{c}\text { Placement } \\
\text { type }\end{array}$ & Peri-implantitis & $\begin{array}{c}\text { Ex (lost) } \\
\text { status }\end{array}$ & $\begin{array}{l}\text { Follow-up } \\
\text { (months) }\end{array}$ \\
\hline \multirow{3}{*}{59} & \multirow{3}{*}{$\mathrm{F}$} & \multirow{3}{*}{ Healthy } & \multirow{3}{*}{ Yes } & \multirow{3}{*}{ No } & 37 & 8 & 3.3 & $B L$ & Conventional & No & Early loss & 3 \\
\hline & & & & & 36 & 8 & 3.3 & $B L$ & Conventional & No & No & 26 \\
\hline & & & & & 27 & 8 & 4.8 & $\mathrm{TL}$ & Conventional & No & No & 26 \\
\hline \multirow{2}{*}{68} & \multirow{2}{*}{ M } & \multirow{2}{*}{ Healthy } & \multirow{2}{*}{ No } & \multirow{2}{*}{ No } & 22 & 8 & 3.3 & $B L$ & Conventional & No & Early loss & 4 \\
\hline & & & & & 26 & 8 & 3.3 & $\mathrm{TL}$ & Conventional & No & Early loss & 4 \\
\hline 56 & M & Healthy & Yes & Yes & 14 & 8 & 4.1 & $B L$ & Conventional & Yes & No & 6 \\
\hline \multirow{2}{*}{55} & \multirow{2}{*}{ M } & \multirow{2}{*}{ Healthy } & \multirow{2}{*}{ No } & \multirow{2}{*}{ Yes } & 47 & 4 & 4.8 & $\mathrm{TL}$ & Conventional & Yes & No & 6 \\
\hline & & & & & 45 & 8 & 4.1 & $B L$ & Conventional & Yes & Late loss & 22 \\
\hline 62 & $\mathrm{~F}$ & DM-II & Yes & No & 27 & 8 & 4.1 & $B L$ & Conventional & No & No & 12 \\
\hline 48 & M & Healthy & Yes & No & 27 & 6 & 4.1 & $\mathrm{TL}$ & Conventional & Yes & Late loss & 12 \\
\hline 21 & M & Healthy & Yes & No & 14 & 8 & 4.1 & $\mathrm{TL}$ & Conventional & Yes & No & 14 \\
\hline 54 & M & DM-I & No & No & 27 & 8 & 4.8 & $\mathrm{TL}$ & Immediate & Yes & Late loss & 19 \\
\hline 53 & $\mathrm{~F}$ & Healthy & No & Yes & 46 & 8 & 3.3 & $B L$ & Conventional & Yes & No & 20 \\
\hline 47 & $\mathrm{~F}$ & Healthy & No & Yes & 14 & 8 & 4.1 & $B \mathrm{~L}$ & Conventional & No & No & 20 \\
\hline 65 & M & Healthy & No & Yes & 36 & 8 & 3.3 & $B \mathrm{~L}$ & Conventional & No & No & 24 \\
\hline 55 & M & DM-II & No & No & 46 & 9 & 3.5 & $\mathrm{BL}$ & Conventional & Yes & Late loss & 27 \\
\hline 69 & M & Healthy & No & Yes & 26 & 8 & 3.3 & $\mathrm{TL}$ & Conventional & Yes & Late loss & 27 \\
\hline \multirow{2}{*}{50} & $M$ & Healthy & Yes & Yes & 16 & 6 & 4.1 & $\mathrm{TL}$ & Conventional & Yes & No & 29 \\
\hline & IVI & теліпу & Tes & Tes & 25 & 6 & 4.1 & $\mathrm{TL}$ & Conventional & Yes & No & 29 \\
\hline 72 & $\mathrm{~F}$ & DM-II & No & Yes & 26 & 8 & 4.1 & $B L$ & Conventional & Yes & Late loss & 32 \\
\hline 60 & M & Healthy & Yes & No & 15 & 8 & 4.1 & $\mathrm{TL}$ & Conventional & No & No & 34 \\
\hline 44 & $M$ & Healthy & $\mathrm{No}$ & $\mathrm{No}$ & 26 & 6 & 4.1 & $\mathrm{TL}$ & Conventional & Yes & No & 36 \\
\hline 37 & in & . & (10 & (1) & 16 & 6 & 4.8 & $\mathrm{TL}$ & Conventional & Yes & No & 39 \\
\hline 55 & M & Healthy & No & No & 37 & 8 & 3.75 & $B L$ & Conventional & Yes & No & 37 \\
\hline 49 & $M$ & Healthy & Yes & Yes & 16 & 9 & 4.5 & $\mathrm{BL}$ & Conventional & Yes & Late loss & 38 \\
\hline (7) & 政 & 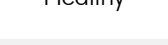 & Tos & Tos & 23 & 9 & 4 & $B L$ & Conventional & Yes & No & 52 \\
\hline 57 & $M$ & Healthy & $\mathrm{No}$ & Yes & 26 & 8 & 3.3 & $\mathrm{TL}$ & Conventional & Yes & Late loss & 42 \\
\hline ( & ivi & - & 100 & Tes & 16 & 8 & 3.3 & $\mathrm{TL}$ & Conventional & Yes & Late loss & 49 \\
\hline 49 & $\mathrm{~F}$ & Healthy & Yes & Yes & 15 & 8 & 4.1 & $\mathrm{TL}$ & Conventional & Yes & No & 43 \\
\hline 56 & M & Hypertension & No & No & 27 & 8 & 4.1 & $B \mathrm{~L}$ & Conventional & No & No & 49 \\
\hline & & & & & 24 & 8 & 4.1 & $\mathrm{TL}$ & Conventional & Yes & Late loss & 51 \\
\hline 42 & $\mathrm{~F}$ & Healthy & Yes & No & 26 & 8 & 4.1 & $\mathrm{TL}$ & Conventional & Yes & Late loss & 51 \\
\hline & & & & & 21 & 8 & 4.1 & $B L$ & Conventional & Yes & No & 57 \\
\hline 61 & M & DM-I & No & No & 36 & 9 & 3.5 & $B L$ & Immediate & Yes & No & 58 \\
\hline 54 & $M$ & Hymertencion & Yoc & Yoc & 35 & 9 & 4.5 & $B L$ & Conventional & Yes & Late loss & 63 \\
\hline 34 & $\mathrm{MI}$ & rypenension & Tes & Tes & 37 & 9 & 4.5 & $B L$ & Conventional & Yes & Late loss & 63 \\
\hline 56 & M & Healthy & No & Yes & 45 & 8 & 4.1 & $B L$ & Conventional & Yes & No & 67 \\
\hline 65 & M & DM-II & Yes & Yes & 36 & 9 & 4.5 & $B L$ & Conventional & Yes & Late loss & 72 \\
\hline 50 & $\mathrm{~F}$ & Healthy & No & $\mathrm{No}$ & 25 & 9 & 3.5 & $B L$ & Conventional & No & No & 79 \\
\hline & & Teanny & NO & NO & 26 & 9 & 4.0 & $B L$ & Conventional & No & No & 79 \\
\hline 64 & M & Healthy & No & Yes & 36 & 9 & 3.5 & $B L$ & Conventional & Yes & No & 84 \\
\hline 47 & $\mathrm{~F}$ & Healthy & No & No & 27 & 9 & 5.0 & $B L$ & Conventional & Yes & No & 85 \\
\hline 65 & M & Hypertension & Yes & Yes & 27 & 8 & 5.0 & $B L$ & Conventional & Yes & No & 85 \\
\hline 47 & M & Healthy & Yes & No & 15 & 9 & 3.5 & $\mathrm{BL}$ & Conventional & Yes & No & 85 \\
\hline 48 & $M$ & Healthy & & & 26 & 9 & 5.0 & $\mathrm{BL}$ & Conventional & Yes & Late loss & 90 \\
\hline 40 & $M$ & mearny & res & res & 34 & 9 & 3.5 & $\mathrm{BL}$ & Conventional & Yes & Late loss & 90 \\
\hline
\end{tabular}


Risk factors associated with short dental implant success: a long-term retrospective evaluation of patients followed up for up to 9 years

Table 5. Univariate binary logistic regression for short implant success at the implant level.

\begin{tabular}{|c|c|c|c|c|c|c|c|}
\hline \multirow{2}{*}{ Variables } & \multirow{2}{*}{ B } & \multirow{2}{*}{ SE } & \multirow{2}{*}{ Wald } & \multirow{2}{*}{ p-value } & \multirow{2}{*}{ OR } & \multicolumn{2}{|c|}{$95 \% \mathrm{Cl}$ for $\mathrm{OR}$} \\
\hline & & & & & & Lower & Upper \\
\hline Implant manufacturer & -0.454 & 0.332 & 1.877 & 0.171 & 0.635 & 0.332 & 1.216 \\
\hline Anatomical location of implant & -0.282 & 0.206 & 1.881 & 0.170 & 0.754 & 0.504 & 1.129 \\
\hline Implant diameter & -0.014 & 0.409 & 0.001 & 0.972 & 0.986 & 0.443 & 2.196 \\
\hline Implant length & 0.283 & 0.217 & 1.696 & 0.193 & 1.327 & 0.867 & 2.031 \\
\hline Implant design & 0.630 & 0.468 & 1.808 & 0.179 & 1.877 & 0.750 & 4.702 \\
\hline Implant placement & 0.358 & 0.708 & 0.255 & 0.613 & 1.430 & 0.357 & 5.728 \\
\hline Sex (female) & 1.119 & 0.427 & 6.869 & 0.009 & 3.060 & 1.326 & 7.064 \\
\hline Age (years) & -0.025 & 0.019 & 1.595 & 0.207 & 0.976 & 0.939 & 1.014 \\
\hline History of periodontitis & -0.922 & 0.400 & 5.303 & 0.021 & 0.398 & 0.182 & 0.872 \\
\hline Smoking habit & -0.068 & 0.012 & 30.905 & 0.001 & 0.934 & 0.912 & 0.957 \\
\hline Diabetes mellitus & 0.196 & 0.385 & 0.258 & 0.611 & 1.216 & 0.572 & 2.588 \\
\hline Other systemic diseases & 2.803 & 0.910 & 9.499 & 0.052 & 16.499 & 2.775 & 98.096 \\
\hline Intake of medication & 1.683 & 0.852 & 3.904 & 0.058 & 5.381 & 1.014 & 28.565 \\
\hline
\end{tabular}

B: beta coefficient, SE: standard errors, OR: odds ratio, $95 \% \mathrm{Cl}$ : $95 \%$ confidence interval.

Table 6. Univariate binary logistic regression for short implant success at patient level.

\begin{tabular}{|c|c|c|c|c|c|c|c|}
\hline \multirow{2}{*}{ Variables } & \multirow{2}{*}{ B } & \multirow{2}{*}{ SE } & \multirow{2}{*}{ Wald } & \multirow{2}{*}{$\mathrm{p}$-value } & \multirow{2}{*}{ OR } & \multicolumn{2}{|c|}{$95 \% \mathrm{Cl}$ for $\mathrm{OR}$} \\
\hline & & & & & & Lower & Upper \\
\hline Sex (female) & 1.357 & 0.48 & 7.997 & 0.005 & 3.885 & 1.517 & 9.95 \\
\hline Age (years) & -0.032 & 0.022 & 2.214 & 0.137 & 0.968 & 0.928 & 1.01 \\
\hline History of periodontitis & -0.921 & 0.456 & 4.085 & 0.043 & 0.398 & 0.163 & 0.972 \\
\hline Smoking habit & -0.083 & 0.02 & 17.433 & 0.001 & 0.92 & 0.885 & 0.957 \\
\hline Diabetes mellitus & 0.176 & 0.469 & 0.141 & 0.707 & 1.193 & 0.476 & 2.99 \\
\hline Other systemic diseases & 2.478 & 1.092 & 5.15 & 0.053 & 11.915 & 1.402 & 101.272 \\
\hline Intake of medication & 1.882 & 1.104 & 2.907 & 0.088 & 6.565 & 0.755 & 57.104 \\
\hline
\end{tabular}

B: beta coefficient, SE: standard errors, OR: odds ratio, $95 \% \mathrm{Cl}$ : $95 \%$ confidence interval.

univariate regression analyses were performed to identify the relationship between each independent implant- and patient-based variable and short implant success separately. In the regression models, only female sex, history of periodontitis, and smoking were shown to significantly affect short implant success in implant- and patient-based analyses.

Periodontitis is an inflammatory condition of the periodontium in which the host immune inflammatory response induced by bacterial colonization leads to the release of several inflammatory mediators, resulting in connective tissue destruction and bone resorption. ${ }^{4,31}$ Some studies have asserted that patients with a history of periodontitis have a higher risk of exposure to biological complications (i.e., peri-implantitis and marginal bone loss) and demonstrate lower implant success and/or survival rates than periodontally healthy patients. ${ }^{2,4,32,33} \mathrm{In}$ the current study, peri-implantitis was shown to be the primary cause of short implant failure, and approximately $44 \%$ of these cases occurred in patients with a history of periodontitis, corroborating the findings of previous studies. Nevertheless, only a few studies have reported the influence of periodontitis on the success rate of short implants. ${ }^{9,29,34}$ In the studies by Omran et al. and Correia et al., no significant 
differences were found in terms of survival rates of short implants between patients with or without a history of periodontitis.,34 On the contrary, the present study observed a significant negative relationship between a history of periodontitis and short implant success. The implant- and patient-based analyses indicated that patients with a history of periodontitis are at a greater risk of short dental implant failure. A recent prospective study reported similar results in which a great majority of participants had chronic periodontitis $(77.1 \%)$, and the authors concluded that proper periodontal treatment prior to implant placement is necessary for patients with periodontitis and that a strict, supportive periodontal program is strongly recommended for the long-term success of short implants. ${ }^{29}$

The deleterious effect of smoking on oral health is well documented in the literature. Smoking increases the expression and deposition of advanced glycation end products in the periodontal tissue followed by the upregulation of pro-inflammatory cytokines (i.e., matrix metalloproteinase-1, interleukin-1 $\beta$, and interleukin-6), promoting tissue damage, development of periodontal diseases, and alveolar bone resorption. ${ }^{16,35}$ Additionally, smoking has been reported as a primary patient-related risk factor for dental implant loss, ${ }^{35}$ and several studies have found lower implant success and/or survival rates in smokers than in nonsmokers, ${ }^{1,3,49,32,33,36,37}$ supporting the present study findings of a significant association between smoking and short implant success. According to implant- and patient-based regression analyses, short implant success is 0.934 and 0.920 times less likely to occur in smokers than in nonsmokers, respectively. Further, some studies did not observe a significant relationship between smoking and implant survival.,38 In a recent clinical study, Abduljabbar et al. ${ }^{16}$ compared clinical and radiographic inflammatory parameters of short implants and reported no significant differences between smokers and nonsmokers. However, the study comprised relatively young males (aged approximately 40 years) whose smoking history consisted of no more than nine packs annually. Additionally, all participants underwent biannual supportive periodontal therapy and were instructed to maintain satisfactory oral hygiene. Although the outcomes of this study stress the importance of strict oral hygiene maintenance protocols among smokers, further studies including patients belonging to various age groups and different smoker types are required to verify the correlation between short implant success and oral hygiene maintenance protocols. Furthermore, strong evidence shows that smoking poses a greater risk of biological implant complications, i.e., peri-implant diseases. ${ }^{32,35,36,39} \mathrm{In}$ the present study, smokers comprised more than half of peri-implantitis cases (52.94\%), supporting the findings reported by Rinke et al. ${ }^{40}$ who reported an increased rate of peri-implantitis among smokers and those by Karoussis et al. ${ }^{6}$ who reported a 31-fold higher risk of peri-implantitis among smokers than among nonsmokers.

In the recent literature, the influence of sex on dental implant therapy success remains controversial. Although several studies have reported no significant sex-specific differences in terms of implant failure rates, ${ }^{3,11}$ some have reported a strong correlation between male sex and implant failure. ${ }^{37,41,42}$ In the current study, female sex had a significant positive association with short implant success, possibly explained by the lower rate of a history of periodontitis and heavy smoking in females than in males.

Chronic hyperglycemia is a well-known risk factor for dental implant therapy, and consensus shows that dental implants can remain clinically and functionally stable over a long period in hyperglycemic patients under optimal glycemic control. ${ }^{1,3,4}$ However, very few studies on short implants have included diabetic subjects or examined the influence of DM on short implant success. In a study by Omran et al., ${ }^{9} \mathrm{DM}$ was not found to have a significant impact on short implant survival. In addition, a recent clinical study with a 3-year follow-up observed no significant difference in terms of clinical and radiographic parameters of short implants between patients with and without type II DM..$^{10}$ Similar to these results, the current study found that neither type I nor type II DM is a risk factor for the long-term success of short implants.

Greater bone-to-implant contact has been achieved with the development of implant surface modifications, leading to higher success rates of short implants than shorter machine-surfaced implants. ${ }^{8,23,30,38}$ In 
this study, four short implant systems with different types of surface roughness were examined, and the success rates of all four short implant brands were comparable. Similar results have also been presented in other studies comparing short implants with different designs and surface characteristics. ${ }^{9,43}$

In the current study, although mandibular short implants $(92.89 \%)$ had a higher success rate than maxillary short implants (87.83\%), maxillary insertion of short implants was not found to be a risk factor for implant success. In contrast to this finding, Villarinho et $a l .{ }^{44}$ indicated that short implants placed in the posterior mandible region showed a higher risk of failure than those placed in the posterior maxilla region. However, many other studies have reported no difference in terms of survival rates of short implants with regard to their anatomical location. ${ }^{8,9,11}$ Furthermore, neither implant length and diameter nor the type of implant placement (conventional and immediate) was found to have a significant impact on short implant success in the present study. In a systematic review, Telleman et al. ${ }^{28}$ reported higher estimated survival rates with the increasing length of short implants placed in partially edentulous patients. On the other hand, many clinical trials and retrospective studies have reported results similar to those of the current study $y^{9,11,26}$ and advocated that length and/or diameter are not significant factors affecting short implant survival. Moreover, limited information is available regarding the influence of immediate placement on the success or survival of short implants. A prospective study reported that four of five losses occurred with immediately placed short implants. However, the overall survival rate of short implants was also found to be lower $(80 \%)$ than that reported in recent studies, possibly attributed to the design of the implants used in that study. ${ }^{45}$ More recently, Anitua et al. ${ }^{11}$ investigated the impact of individual variables on short implant success in which immediate placement was examined in a "special techniques" category that included sinus elevation and split-crest expansion. Although this group included very few implants $(n=11)$, which may reduce the power of statistical analysis, no relationship was reported between the implementation of special techniques and short implant success. In the present study, a total of 45 short implants were immediately placed, and only three failures were observed during the follow-up period.

The findings of the current study may contribute important information to the literature regarding the influence of possible risk factors on the long-term success of short implants. However, some limitations should be considered when interpreting these results. First, this is a retrospective study, which relies on the accuracy and completeness of the data available in patients' charts; this may pose a risk of missing data due to gaps in information or incomplete records. Moreover, only short implants with cement-retained crowns and bridges were included, preventing the ability to determine the influence of different types of restorations on the success of short implants. On the other hand, regardless of any medical condition, smoking habit, or periodontal disease history, all patients treated with short implants were examined with robust statistical analyses, minimizing selection bias and increasing the applicability of the study findings to the general population.

\section{Conclusions}

A history of smoking and periodontitis has significant negative influence on the success of short implants. However, there is no evidence to support an association between other potential risk factors and short implant success; therefore, clinicians need to be aware of the potential influence of the associated risk factors and make treatment decisions accordingly.

\section{References}

1. Anner R, Grossmann Y, Anner Y, Levin L. Smoking, diabetes mellitus, periodontitis, and supportive periodontal treatment as factors associated with dental implant survival: a long-term retrospective evaluation of patients followed for up to 10 years. Implant Dent. 2010 Feb;19(1):57-64. https://doi.org/10.1097/ID.0b013e3181bb8f6c 
2. Anitua E, Orive G, Aguirre JJ, Ardanza B, Andia I. 5-year clinical experience with BTI dental implants: risk factors for implant failure. J Clin Periodontol. 2008 Aug;35(8):724-32. https://doi.org/10.1111/j.1600-051X.2008.01248.x

3. Chrcanovic BR, Kisch J, Albrektsson T, Wennerberg A. Factors influencing early dental implant failures. J Dent Res. 2016 Aug;95(9):995-1002. https://doi.org/10.1177/0022034516646098

4. Klokkevold PR, Han TJ. How do smoking, diabetes, and periodontitis affect outcomes of implant treatment? Int J Oral Maxillofac Implants. 2007;22 (Suppl):173-202.

5. Simonis $P$, Dufour T, Tenenbaum H. Long-term implant survival and success: a 10-16-year follow-up of non-submerged dental implants. Clin Oral Implants Res. 2010 Jul;21(7):772-7. https://doi.org/10.1111/j.1600-0501.2010.01912.x

6. Karoussis IK, Salvi GE, Heitz-Mayfield LJ, Bragger U, Hammerle CH, Lang NP. Long-term implant prognosis in patients with and without a history of chronic periodontitis: a 10-year prospective cohort study of the ITI Dental Implant System. Clin Oral Implants Res. 2003 Jun;14(3):329-39.

7. Karoussis IK, Müller S, Salvi GE, Heitz-Mayfield LJ, Bragger U, Lang NP. Association between periodontal and peri-implant conditions: a 10-year prospective study. Clin Oral Implants Res. 2004 Feb;15(1):1-7.

8. Annibali S, Cristalli MP, Dell'Aquila D, Bignozzi I, La Monaca G, Pilloni A. Short dental implants: a systematic review. J Dent Res. 2012 Jan;91(1):25-32. https://doi.org/10.1177/0022034511425675

9. Omran MT, Miley DD, McLeod DE, Garcia MN. Retrospective assessment of survival rate for short endosseous dental implants. Implant Dent. 2015 Apr;24(2):185-91. https://doi.org/10.1097/ID.0000000000000229

10. Al Amri MD, Abduliabbar TS, Al-Johany SS, Al Rifaiy MQ, Alfarraj Aldosari AM, Al-Kheraif AA. Comparison of clinical and radiographic parameters around short ( 6 to $8 \mathrm{~mm}$ in length) and long (11 mm in length) dental implants placed in patients with and without type 2 diabetes mellitus: 3-year follow-up results. Clin Oral Implants Res. 2017 Oct;28(10):1182-7. https://doi.org/10.1111/clr.12938

11. Anitua E, Pinas L, Begona L, Orive G. Long-term retrospective evaluation of short implants in the posterior areas: clinical results after 10-12 years. J Clin Periodontol. 2014 Apr;41(4):404-11. https://doi.org/10.1111/jcpe.12222

12. Stellingsma K, Raghoebar GM, Visser A, Vissink A, Meijer HJ. The extremely resorbed mandible, 10 -year results of a randomized controlled trial on 3 treatment strategies. Clin Oral Implants Res. 2014 Aug;25(8):926-32. https://doi.org/10.1111/clr.12184

13. Friberg B, Grondahl K, Lekholm U, Branemark PI. Long-term follow-up of severely atrophic edentulous mandibles reconstructed with short Branemark implants. Clin Implant Dent Relat Res. 2000;2(4):184-9. https://doi.org/10.1111/j.1708-8208.2000.tb00116.x

14. Van Assche N, Michels S, Quirynen M, Naert I. Extra short dental implants supporting an overdenture in the edentulous maxilla: a proof of concept. Clin Oral Implants Res. 2012 May;23(5):567-76. https://doi.org/10.1111/j.1600-0501.2011.02235.x

15. Borba M, Deluiz D, Lourenco EJV, Oliveira L, Tannure PN. Risk factors for implant failure: a retrospective study in an educational institution using GEE analyses. Braz Oral Res. 2017 Aug;31:1-7. https://doi.org/10.1590/1807-3107BOR-2017.vol31.0069

16. Abduljabbar T, Al-Hamoudi N, Al-Sowygh ZH, Alajmi M, Javed F, Vohra F. Comparison of peri-implant clinical and radiographic status around short (6 mm in length) dental implants placed in cigarette-smokers and never-smokers: Six-year follow-up results. Clin Implant Dent Relat Res. 2018 Feb;20(1):21-25. https://doi.org/10.1111/cid.12564

17. Le BT, Follmar T, Borzabadi-Farahani A. Assessment of short dental implants restored with single-unit nonsplinted restorations. Implant Dent. 2013 Oct;22(5):499-502. https://doi.org/10.1097/ID.0b013e31829afaf2

18. Albrektsson T, Zarb G, Worthington P, Eriksson AR. The long-term efficacy of currently used dental implants: a review and proposed criteria of success. Int J Oral Maxillofac Implants. 1986 Summer;1(1):11-25.

19. Kang N, Wu YY, Gong P, Yue L, Ou GM. A study of force distribution of loading stresses on implant-bone interface on short implant length using 3-dimensional finite element analysis. Oral Surg Oral Med Oral Pathol Oral Radiol. 2014 Nov;118(5):519-23. https://doi.org/10.1016/i.0ooo.2014.05.021

20. Winkler S, Morris HF, Ochi S. Implant survival to 36 months as related to length and diameter. Ann Periodontol. 2000 Dec;5(1):22-31.

21. Herrmann I, Lekholm U, Holm S, Kultje C. Evaluation of patient and implant characteristics as potential prognostic factors for oral implant failures. Int J Oral Maxillofac Implants. 2005 Mar-Apr;20(2):220-30.

22. Tong DC, Rioux K, Drangsholt M, Beirne OR. A review of survival rates for implants placed in grafted maxillary sinuses using meta-analysis. Int J Oral Maxillofac Implants. 1998 Mar-Apr;13(2):175-82.

23. Sanchez-Garces MA, Costa-Berenguer X, Gay-Escoda C. Short implants: a descriptive study of 273 implants. Clin Implant Dent Relat Res. 2012 Aug;14(4):508-16. https://doi.org/10.1111/j.1708-8208.2010.00301.x

24. Mertens C, Meyer-Baumer A, Kappel H, Hoffmann J, Steveling HG. Use of 8-mm and 9-mm implants in atrophic alveolar ridges: 10-year results. Int J Oral Maxillofac Implants. 2012 Nov-Dec;27(6):1501-8.

25. Lops D, Bressan E, Pisoni G, Cea N, Corazza B, Romeo E. Short implants in partially edentuolous maxillae and mandibles: a 10 to 20 years retrospective evaluation. Int J Dent. 2012;2012:1-8. https://doi.org/10.1155/2012/351793

26. Lai HC, Si MS, Zhuang LF, Shen H, Liu YL, Wismeijer D. Long-term outcomes of short dental implants supporting single crowns in posterior region: a clinical retrospective study of 5-10 years. Clin Oral Implants Res. 2013 Feb;24(2):230-7. https://doi.org/10.1111/i.1600-0501.2012.02452.x 
- Risk factors associated with short dental implant success: a long-term retrospective evaluation of patients followed up for up to 9 years

27. Monje A, Chan HL, Fu JH, Suarez F, Galindo-Moreno P, Wang HL. Are short dental implants (<10 mm) effective? a meta-analysis on prospective clinical trials. J Periodontol. 2013 Jul;84(7):895-904. https://doi.org/10.1902/jop.2012.120328

28. Telleman G, Raghoebar GM, Vissink A, den Hartog L, Huddleston Slater JJ, Meijer HJ. A systematic review of the prognosis of short $(<10 \mathrm{~mm}$ ) dental implants placed in the partially edentulous patient. J Clin Periodontol. 2011 Jul;38(7):667-76. https://doi.org/10.1111/j.1600-051X.2011.01736.x

29. Han J, Zhang X, Tang Z, Zhang L, Shi D, Meng H. A prospective, multicenter study assessing the DENTSPLY Implants, OsseoSpeed( ${ }^{\text {TM }}$ ) TX, length $6 \mathrm{~mm}$ in the posterior maxilla and mandible: a 1-year follow-up study. Clin Oral Implants Res. 2016 Apr;27(4):452-7. https://doi.org/10.1111/clr.12587

30. Renouard F, Nisand D. Short implants in the severely resorbed maxilla: a 2-year retrospective clinical study. Clin Implant Dent Relat Res. $2005 ; 7(1): 104-10$.

31. Yucel-Lindberg T, Bage T. Inflammatory mediators in the pathogenesis of periodontitis. Expert Rev Mol Med. 2013 Aug;15:1-22. https://doi.org/10.1017/erm.2013.8

32. Pimentel SP, Shiota R, Cirano FR, Casarin RCV, Pecorari VGA, Casati MZ, et al. Occurrence of peri-implant diseases and risk indicators at the patient and implant levels: A multi-level cross-sectional study. J Periodontol. 2018 Sep;89(9):1091-100. https://doi.org/10.1002/JPER.17-0599

33. Mohanty R, Sudan PS, Dharamsi AM, Mokashi R, Misurya AL, Kaushal P. Risk assessment in long-term survival rates of dental implants: a prospective clinical study. J Contemp Dent Pract. 2018 May; 19(5):587-590.

34. Correia F, Gouveia S, Felino AC, Costa AL, Almeida RF. Survival rate of dental implants in patients with history of periodontal disease: A retrospective cohort study. Int J Oral Maxillofac Implants. 2017 Jul/Aug;32(4):927-34. https://doi.org/10.11607/jomi.3732

35. Kasat V, Ladda R. Smoking and dental implants. J Int Soc Prev Community Dent. 2012 Jul;2(2):38-41. https://doi.org/10.4103/2231-0762.109358

36. Strietzel FP, Reichart PA, Kale A, Kulkarni M, Wegner B, Kuchler I. Smoking interferes with the prognosis of dental implant treatment: a systematic review and meta-analysis. J Clin Periodontol. 2007 Jun;34(6):523-44.

37. Grisar K, Sinha D, Schoenaers J, Dormaar T, Politis C. Retrospective analysis of dental implants placed between 2012 and 2014: Indications, risk factors, and early survival. Int J Oral Maxillofac Implants. 2017 May/June;32(3):649-54. https://doi.org/10.11607/jomi.5332

38. Kumar A, Jaffin RA, Berman C. The effect of smoking on achieving osseointegration of surface-modified implants: a clinical report. Int J Oral Maxillofac Implants. 2002 Nov-Dec;17(6):816-9.

39. BinShabaib MS, Mehmood A, Akram Z, ALHarthi SS. Peri-implant clinical and radiographic status and whole salivary cotinine levels among cigarette and waterpipe smokers and never-smokers. J Oral Sci. 2018;60(2):247-52. https://doi.org/10.2334/josnusd.17-0221

40. Rinke S, Ohl S, Ziebolz D, Lange K, Eickholz P. Prevalence of periimplant disease in partially edentulous patients: a practice-based cross-sectional study. Clin Oral Implants Res. 2011 Aug;22(8):826-33. https://doi.org/10.1111/j.1600-0501.2010.02061.x

41. Zupnik J, Kim SW, Ravens D, Karimbux N, Guze K. Factors associated with dental implant survival: a 4-year retrospective analysis. J Periodontol. 2011 Oct;82(10):1390-5. https://doi.org/10.1902/jop.2011.100685

42. Song S, Lee, JK, Um HS, Chang BS. Factors affecting the survival of implants: a long-term retrospective study. J Dent Rehabil Appl Sci 2015;31(1):10-19. https://doi.org/10.14368/jdras.2015.31.1.10

43. Atieh MA, Zadeh H, Stanford CM, Cooper LF. Survival of short dental implants for treatment of posterior partial edentulism: a systematic review. Int J Oral Maxillofac Implants. 2012 Nov-Dec;27(6):1323-31.

44. Villarinho EA, Triches DF, Alonso FR, Mezzomo LAM, Teixeira ER, Shinkai RSA. Risk factors for single crowns supported by short (6-mm) implants in the posterior region: A prospective clinical and radiographic study. Clin Implant Dent Relat Res. 2017 Aug;19(4):671-80. https://doi.org/10.1111/cid.12494

45. Grunder U, Polizzi G, Goené R, Hatano N, Henry P, Jackson WJ, et al. A 3-year prospective multicenter follow-up report on the immediate and delayed-immediate placement of implants. Int J Oral Maxillofac Implants. 1999 Mar-Apr;14(2):210-6. 